$\begin{array}{ll} & \text { Preprints are preliminary reports that have not undergone peer review. } \\ \text { Research Square } & \text { They should not be considered conclusive, used to inform clinical practice, } \\ \text { or referenced by the media as validated information. }\end{array}$

\title{
The Effect of Cognitive Functional Therapy for Chronic Nonspecific Low Back Pain: Systematic Review and Meta-analysis
}

Takahiro Miki ( $\nabla$ tkhr.mk@gmail.com)

Sapporo Maruyama Orthopedic Hospital https://orcid.org/0000-0002-0648-2675

Yu Kondo

Sapporo Maruyama Orthopedic Hospital

Hiroshi kurakata

Yumenomachi Home Nursing care and rehabilitation service

Eva Buzasi

University College London

Tsuneo Takebayashi

Sapporo Maruyama Orthopedic Hospital

Hiroshi Takasaki

Saitama Prefectural University Faculty of Health Science and Welfare: Saitama Kenritsu Daigaku Hoken Iryo Fukushi Gakubu Daigakuin Hoken Iryo Fukushigaku Kenkyuka

Research

Keywords: cognitive functional therapy, chronic nonspecific low back pain, fear of physical activity

Posted Date: March 30th, 2021

DOI: https://doi.org/10.21203/rs.3.rs-357578/v1

License: () (1) This work is licensed under a Creative Commons Attribution 4.0 International License. Read Full License 


\section{Abstract}

Background: To apply the Bio-Psych-Social (BPS) model into clinical practice, it is important not to focus on psychosocial domains only since biomedical factors can also contribute to chronic pain conditions. The cognitive functional therapy (CFT) is the management system based on the BPS model for chronic nonspecific low back pain (CNSLBP).

Objectives: To compare CFT with the other interventions for CNSLBP regarding pain, disability/functional status, QoL and psychological factors.

Design: Systematic review and meta-analysis.

Method: Literature Search was conducted in electronic search engines. Enrolled participants included 1) CNSLBP and 2) primary, secondary, or tertiary care patients. CFT was the interventions included. Comparisons were any types of treatment.

Results: Three studies met the eligibility criteria. The total number of participants was 336. For pain intensity, MD [95\% Cls] was -2.78 [-2.78-0.02] and -1.01 [-1.92--0.10] at intermediate and long term for two studies, respectively. About disability/functional status, SMD [95\% Cls] was -0.76 [-1.46--0.07] at the intermediate for three studies and MD [95\% Cls] was -0.84 [-11.47--5.49] at long term for two studies. About fear of physical activity, MD [95\% Cls] was -3.01 $[-5.14--0.88]$ and $-3.56[-6.43--0.68]$ at intermediate and long term for two studies, respectively. No studies reported scores associated with QOL. All the quality of the evidence was very low.

Conclusions: Three studies were included and the quality of all the evidence was very low. Although the study found statistically significant differences in some measures, the effectiveness of the CFT will need to be re-evaluated in the future.

PROSPERO registration number CRD42020158182

\section{Background}

The Bio-Psych-Social (BPS) model of care is recommended in clinical practice guidelines for chronic nonspecific low back pain (CNSLBP) [1]. However, implementing the BPS approach for CNSLBP has not been conducted well by physical therapists [2]. One reason is the lack confidence in the interventions based on the BPS model [3]. To apply the BPS model in clinical practice, it is important to not focus only on psychosocial domains because biomedical factors can also contribute to chronic pain conditions [4]. Cognitive - behavioral therapy (CBT) is effective for CNSLBP but only to some extent [5]. CBT is limited in that it is a psychological approach and not a BPS approach [6]. Recently, Peter O'Sullivan and colleagues introduced cognitive - functional therapy (CFT) [7]. CFT is an example of physical therapists using the BPS approach for CNSLBP and is increasingly of interest.

Characteristics of the CFT have been explained in detail in a previous study [7]. Briefly, the CFT helps CNSLBP patients understand their pain features and develops an individually tailored management strategy. The CFT uses a multidimensional clinical reasoning framework [8] and identifies key modifiable targets for management in each patient through careful listening to their individual story, and experiential learning on responses to pain by challenging expectations of pain in guided behavioural experiments, which has components of a exposure-based approach. Using an exposure-based approach is effective with individuals who have a strong level of fear, which is one factor that can lead to a poor prognosis in patients with low back pain (LBP) [9]. The CFT aims to enable the therapist to lead the patient to effectively perform self-management using the three primary components; "Making sense of pain", "Exposure with control", and "Lifestyle change" (See Appendix 1).

In order to summarize the evidence, this systematic review with meta-analysis of randomized controlled trials (RCTs) aimed to evaluate the effectiveness of the CFT by comparing the CFT and the other treatments of pain, disability, quality of life, and psychological status among individuals with CNSLBP.

\section{Materials And Methods}

\section{Protocol and registration}

This systematic review was pre-registered in the Prospero Database (CRD42020158182) and followed a guideline for systematic review on musculoskeletal disorders.[10]

\section{Information sources and search}

One author (HK) systematically searched the following databases from inception to Dec 2020: Web of science, CENTRAL, MEDLINE, EMBASE, PsycINFO, EMCARE, CINAHL, AMED and PEDro databases. Although CENTRAL and AMED were not listed in the PROSPERO, a more accurate search was performed. The search strategies are presented in Appendix 2 (See Appendix 2). Moreover, cross-referencing was done to the primary developer of the CFT, Peter O'Sullivan, and relevant literatures cited in the studies were searched manually. Language limitation was removed although initially this was limited to English only during the first registration with the PROSPERO.

\section{Eligibility criteria}

The PICOS framework was used in developing the eligibility criteria. Enrolled participants included 1) patients with chronic LBP; 2) patients from primary, secondary, or tertiary care; and 3) patients without radiating pain to lower extremities. Studies with the following participants were not included in this systematic review: 1) participants with LBP caused by serious pathologies, including infections, neoplasms, metastases, fractures, osteoporosis, rheumatoid arthritis, and radiculopathies; 2) participants with LBP during or immediately following pregnancy; and 3) participants with postoperative back pain. Eligible

Loading [MathJax]/jax/output/CommonHTML/jax.js fication-based CFT as both managements were conceptually comparable, which was confirmed by the primary 
developer, Peter O'Sullivan. Eligible comparisons included any types of interventions other than the CFT or the classification-based CFT. Eligible outcomes included pain intensity, back-specific disability/function status, quality of life, and psychological status. Eligible study design was only the published RCT although it included observational studies in PROSPERO.

\section{Study selection and data collection process}

Screening and full-text inspection were performed by two authors (TM and YK) independently, where publication source, authors, and publication year were not blinded. The screening was based on the information in the title and abstract. Any disagreements on eligibility were resolved through a consensus between the two authors.

\section{Risk of bias in individual studies}

The quality of the argument was assessed using a 10-point PEDro score, which was changed from the Cochrance (RoB) registered in the initial draft of the PROSPERO. This is because the PEDro score was specifically developed to assess the methodological quality of physical therapy trials [11, 12], and established scores are presented. Inclusion criteria for the meta-analysis was high-quality study, which was defined as the study with a PEDro score of 6 or higher $[13,14]$.

\section{The quality of the evidence}

The overall quality of evidence for each meta-analysis was identified using the Grading of Recommendations Assessment, Development and Evaluation (GRADE) system [15] as recommended by the Updated Method Guideline for Systematic Reviews in the Cochrane Back and Neck Group [16]. The GRADE system consists of five items: 1) risk of bias, 2) inconsistency, 3) indirectness, 4) imprecision, and 5) publication bias. Each criterion is rated as high, moderate, low, or very low, and the lowest quality is chosen as the overall quality of evidence. For evidence from RCTs, we started with a rating of high. The quality of evidence on specific outcomes was reduced by one or two levels depending on the performance of specific comparative studies on these five factors. Regarding the risk of bias, the quality of the evidence has been reduced by one point if more than $25 \%$ and two points if more than $50 \%$ of the participants are from studies conducted in low-quality methods (e.g., PEDro score <6). For inconsistency, the quality of evidence has been reduced by one point when the heterogeneity or variability in results was large, as indicated by an $\mathrm{I}^{2}>50 \%$ and reduced by two points when an $\mathrm{I}^{2}>75 \%$. Moreover, another point is reduced if differences among populations, interventions, or outcomes are present. For indirectness, whether the issues addressed in this systematic review differed from the available evidence on populations, interventions, comparisons and outcomes has been assessed. Another point is deducted if there is indirectness in only one area and two points if there is indirectness in two or more areas. As regards imprecision, one point is deducted if the total number of participants was less than 400. In addition, if there is no significant difference in outcomes, the grade is reduced. Regarding publication bias, a funnel plot was created to compare at least ten studies, and from the funnel plot, the quality of the evidence will be reduced by one point if publication bias was suggested.

The two authors (TM and YK) independently assessed GRADE scores in each meta-analysis, and any disagreements were resolved by another author (HK).

\section{Data items and summary measures}

Data were extracted based on the PICOS framework by the two authors (TM and YK) with consensus. Extracted data of the participants included participant source and setting, age, gender, and duration of symptoms. Extracted data of the intervention included description of interventions, duration and number of sessions, therapist training level on the CFT, and delivery type such as individual or group. Extracted data of comparisons included type of intervention and duration and/or number of sessions. Extracted data of outcomes included means and SDs of pain, disability/function status, quality of life, and psychological factors during short, intermediate- and/or long-term follow-ups. In this study, the short term was defined as post-treatment. The intermediate term was defined as $\geq 3$ months and $<12$ months, and the long term was defined as $\geq 12$ months [17]. In the presence of more eligible follow-up points, the follow-up point closest to 6 months was chosen for the intermediate term and the follow-up point closest to 12 months was chosen for the long term. The meta-analysis was attempted using change values from the baseline to each follow-up point first [18]. If there is no change values reported in the study, a corresponding author was contacted by email and was asked to provide the data. If the value of the change is not available, the values at each follow-up point was used for metaanalysis [18]. A reminder email was sent a week after the first contact, and the second reminder was sent two weeks after the first reminder, and if after two weeks, there is still no reply, then no response was considered. Data on serious adverse reports were also extracted, including serious accidents and deaths during the intervention. Extracted data of the study design included country of data collection and source of research grant.

\section{Synthesis of results and statistical analysis}

When multiple datasets of similar outcomes are present, meta-analysis was performed using Review Manager 5 (The Nordic Cochrane Centre, København $\varnothing$, Denmark). The mean difference (MD) or the standardised mean difference (SMD) with $95 \%$ confidence intervals (95\% $\mathrm{Cl}$ ) was calculated using the randomeffect model. The MD was calculated when similar psychometric properties were assessed with similar methods, and the SMD was used when similar psychometric properties were assessed with different methods. The $\mathrm{I}^{2}$ statistic was assessed for heterogeneity among trials, whose interpretations were as follows: $0-40 \%=$ may be insignificant, $30-60 \%=$ moderate heterogeneity, $50-90 \%=$ substantial heterogeneity, and $75-100 \%=$ considerablel heterogeneity [18]. The sensitivity analysis was undertaken when considerable heterogeneity existed and thus the sensitivity analysis was possible.

\section{Results}

\section{Study selection}

Figure 1 presents the flow of the study selection. Disagreement rate between the two authors in the screening process and in the full-text inspection process was $15.5 \%$ and $4.2 \%$, respectively. Four studies [19-22] were eligible. Two studies [19, 22] were from the same study project. However, one study [22] was

Loading [MathJax]/jax/output/CommonHTML/jax.js 
excluded since the data reported were from the same subjects at a 3-year follow-up and no additional data were found that were eligible for extraction in the current systematic review. Consequently, three studies [19-21] were assessed for the risk of bias.

\section{Study characteristics}

The three eligible studies [19] are summarised in Table 1. All studies were RCTs performed by the same research group. All studies reported pain, wherein one study reported change in pain intensity during 15 minutes of rowing and other studies reported average pain intensity over a week using the 11-point numerical rating scale. Therefore, the study was not included in the meta-analysis. The other two studies of pain intensity outcomes were considered to have similar psychometric properties allowing meta-analysis with the MD. All studies reported back-specific disability/functions status: one study used RolandMorris Disability Questionnaire (RMDQ), and the other two studies used the Oswestry Disability Index (ODI). RMDQ and ODI were considered to have similar psychometric properties allowing meta-analysis with the SMD. Regarding psychological status, two studies reported fear of physical activity using the FearAvoidance Beliefs Questionnaire (FABQ), and meta-analysis was performed with the MD. No studies reported scores associated with quality of life. None of the studies reported serious adverse reports. 
Table 1

Summary of the three studies included in the meta-analysis

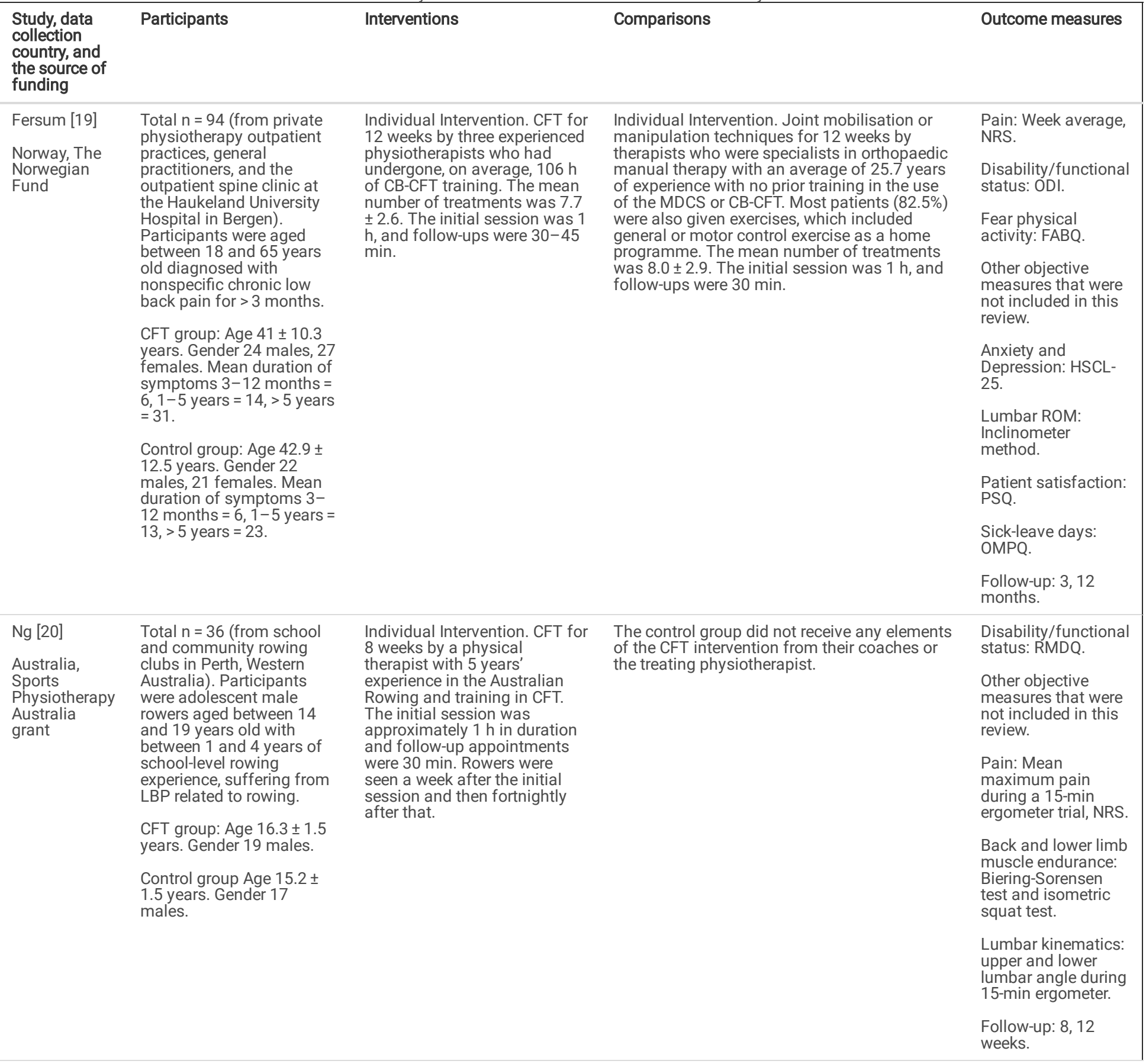




\begin{tabular}{|c|c|c|c|c|}
\hline $\begin{array}{l}\text { Study, data } \\
\text { collection } \\
\text { country, and } \\
\text { the source of } \\
\text { funding }\end{array}$ & Participants & Interventions & Comparisons & Outcome measures \\
\hline $\begin{array}{l}\text { O’Keeffe [21] } \\
\text { Australia, No } \\
\text { funding }\end{array}$ & $\begin{array}{l}\text { Total: } n=206 \text { (from Ballina } \\
\text { Primary Care Centre, } \\
\text { Claremorris Primary Care } \\
\text { Centre and Mayo General } \\
\text { Hospital) } \\
\text { The participants were } \\
\text { between } 18 \text { and } 75 \text { years } \\
\text { of age, CNSLBP for at least } \\
6 \text { months duration. } \\
\\
\text { CFT group: Age } 47.0 \pm 13.2 \\
\text { years. Gender } 24 \text { males, } 82 \\
\text { females. Median duration } \\
\text { of symptoms } 56 \text { (24-120) } \\
\text { months. } \\
\text { Control group: Age } 50.6 \pm \\
14.9 \text { years. Gender } 30 \\
\text { males, } 70 \text { females. Median } \\
\text { duration of symptoms: } 60 \\
\text { (24-156) months. }\end{array}$ & $\begin{array}{l}\text { Individual Intervention. CFT for } \\
12 \text { weeks by three experienced } \\
\text { physiotherapists who had } \\
\text { undergone of CB-CFT training. } \\
\text { Treatment was given weekly } \\
\text { and reduced in frequency over } \\
\text { time. The initial session was } 1 \\
\text { h, and follow-ups were 30- } \\
60 \mathrm{~min} \text {. }\end{array}$ & $\begin{array}{l}\text { Group-based exercise and education } \\
\text { intervention consisting of up to six classes } \\
\text { over } 6-8 \text { weeks, each lasting } \sim 1 \mathrm{~h} \text { and } 15 \mathrm{~min} \text {, } \\
\text { with up to } 10 \text { participants in each class. }\end{array}$ & $\begin{array}{l}\text { Pain: Week average, } \\
\text { NRS. } \\
\text { Disability/functional } \\
\text { status: ODI. } \\
\text { Fear physical } \\
\text { activity: FABQ } \\
\text { Other objective } \\
\text { measures that were } \\
\text { not included in this } \\
\text { review. } \\
\text { Beliefs: BBQ. } \\
\text { Self-efficacy: PSEQ. } \\
\text { Coping: CSQ. } \\
\text { Sleep, depression } \\
\text { and anxiety: SHC. } \\
\text { Stress: DASS. } \\
\text { Patient satisfaction: } \\
\text { PSQ. } \\
\text { Follow-up: Post } \\
\text { intervention, 6, } 12 \\
\text { months. }\end{array}$ \\
\hline $\begin{array}{l}\text { CFT = cognitiv } \\
\text { Multidimensio } \\
\text { PSQ = Patient } \\
\text { Beliefs Questic } \\
\text { DASS = Depres }\end{array}$ & $\begin{array}{l}\text { tional therapy, NRS = Num } \\
\text { assification System, ROM } \\
\text { action Questionnaire, OMP } \\
\text { e, PSEQ = Pain Self-Efficac } \\
\text { Anxiety and Stress Scale. }\end{array}$ & $\begin{array}{l}\text { al Rating Scale, ODI = Oswestr } \\
\text { nge of Motion, RDQ = Roland } \\
\text { Orebro Musculoskeletal Pain } \\
\text { uestionnaire, CSQ = Coping St }\end{array}$ & $\begin{array}{l}\text { ability Index, FABQ = Fear-Avoidance Beliefs } \\
\text { is Disability Questionnaire, HSCL-25 = Hopkir } \\
\text { tionnaire, CNSLBP = chronic non-specific low } \\
\text { ies Questionnaire, SHC = Subjective Health C }\end{array}$ & $\begin{array}{l}\text { tionnaire, MDCS = } \\
\text { mptoms Checklist, } \\
\text { k pain, } \mathrm{BBQ}=\text { Back } \\
\text { laints Inventory, }\end{array}$ \\
\hline
\end{tabular}

\section{Risk of bias within studies}

As all studies included in this study [19] were found in the PEDro online database, the scores from the PEDro online database were used. The quality scores of the three eligible studies [19-21] are summarized in Table 2. For $\mathrm{Ng}$ et al.'s study [20], the sample size was not large, and the participants were somewhat biased toward rowing athletes. $\mathrm{Ng}$ and colleagues did not perform an intention-to-treat analysis and evaluated pain immediately after exercise using a somewhat unique method. O'Keeffe et al.'s study [21] was not blinded, and many participants dropped out during the follow-up. Fersum et al.'s study [19] did not conduct an intention-to-treat analysis and did not have sufficient blinding. In particular, there may be a substantial violation of the intention-to-treat analysis because of the exclusion of 27/121 patients before the 3-month follow-up [23].

Table 2

PEDro scores of included studies

\begin{tabular}{|c|c|c|c|c|c|c|c|c|c|c|c|c|}
\hline Study & $\begin{array}{l}\text { Eligibility } \\
\text { criteria }\end{array}$ & $\begin{array}{l}\text { Random } \\
\text { Allocation }\end{array}$ & $\begin{array}{l}\text { Concealed } \\
\text { Allocation }\end{array}$ & $\begin{array}{l}\text { Groupd } \\
\text { similar } \\
\text { at base } \\
\text { line }\end{array}$ & $\begin{array}{l}\text { Participant } \\
\text { blinding }\end{array}$ & $\begin{array}{l}\text { Therapist } \\
\text { blinding }\end{array}$ & $\begin{array}{l}\text { Assessor } \\
\text { blinding }\end{array}$ & $\begin{array}{l}\text { Adequate } \\
\text { follow-up }\end{array}$ & $\begin{array}{l}\text { Intention- } \\
\text { to-treat } \\
\text { analysis }\end{array}$ & $\begin{array}{l}\text { Between- } \\
\text { group } \\
\text { difference } \\
\text { reported }\end{array}$ & $\begin{array}{l}\text { Point } \\
\text { estimate } \\
\text { and } \\
\text { variability } \\
\text { reported }\end{array}$ & $\begin{array}{l}T \\
(C\end{array}$ \\
\hline Fersum & $Y$ & $Y$ & $Y$ & $\mathrm{Y}$ & $\mathrm{N}$ & $\mathrm{N}$ & $\mathrm{N}$ & $\mathrm{N}$ & $\mathrm{N}$ & Y & $\mathrm{Y}$ & 5 \\
\hline $\mathrm{Ng}$ & $Y$ & $Y$ & $Y$ & $\mathrm{Y}$ & $\mathrm{N}$ & $\mathrm{N}$ & Y & Y & $\mathrm{N}$ & Y & $\mathrm{Y}$ & 7 \\
\hline O'Keeffe & $Y$ & $Y$ & $Y$ & $Y$ & $\mathrm{~N}$ & $\mathrm{~N}$ & $N$ & $\mathrm{~N}$ & $Y$ & $Y$ & $Y$ & 6 \\
\hline
\end{tabular}

Note: Eligibility criteria item does not contribute to total score

\section{Effects of interventions and the quality of the evidence}

No study reported the change values from the baseline to each follow-up point. There was no response from each corresponding author, and the values at each follow-up point were used for meta-analysis (Fig. 2). Meta-analysis was performed for each outcome in the intermediate- and long-terms. In the short term, meta-analysis was not performed because only one study [21] was reported. Also, the quality of the evidence using the GRADE approach is summarized in Table 3. No disagreement was found in any rating between the two authors. 


\section{The CFT versus other treatments for pain intensity for the intermediate-term}

Regarding pain intensity at the intermediate-term period, data from the two studies $[19,21]$ were synthesised. The cumulated sample size of participants in the CFT and other treatments groups was 157 and 143 , respectively. A statistically significant overall effect was not detected $(P=0.05, \mathrm{MD}[95 \%$ Cls] $=-2.78[-2.78$ - 0.02]), indicating that the CFT is not superior to other treatments in terms of pain intensity at the intermediate-term period. The $I^{2}$ value was $87 \%$, indicating substantial heterogeneity. The forest plot is shown in Fig. 2a. The quality of the evidence using the GRADE approach was very low (Table 3).

\section{The CFT versus other treatments for pain intensity for the long-term}

Regarding pain intensity at the long-term period, data from the two studies [19] were synthesised. The cumulated sample size of participants in the CFT and other treatments groups was 157 and 143 participants, respectively. A statistically significant overall effect was detected $(P=0.03, \mathrm{MD}[95 \% \mathrm{Cls}]=-1.01$ [-1.92--0.10]), indicating that the CFT is superior to other treatments in terms of pain intensity at the long-term period. The $\mathrm{I}^{2}$ value was $64 \%$, indicating substantial heterogeneity. The forest plot is shown in Fig. 2b. The quality of the evidence using the GRADE approach was very low (Table 3).

The CFT versus other treatments for disability/functional status for the intermediate-term

Regarding disability/functional status at the intermediate-term period, data from the three studies [19-21] were synthesised, and the forest plot is shown in Fig. 2c. The cumulated sample size of participants in the CFT and other treatments groups was 175 and 158 , respectively. Statistically significant overall effect was detected $(P=0.03$, SMD [95\% Cls] $=-0.76[-1.46--0.07])$, indicating that the CFT is superior to other treatments in terms of disability/functional status at the intermediate-term period. The $\mathrm{I}^{2}$ value was $86 \%$, indicating considerable heterogeneity. The quality of the evidence using the GRADE approach was very low (Table 3).

Sensitivity analyses were conducted for the comparison disability/functional status at the intermediate-term period with the exception of Fersum et al.'s study (Fig. 2d) [19]. A statistically significant overall effect was detected $(P=0.0003, \mathrm{SMD}[95 \% \mathrm{Cls}]=-0.47[-0.73--0.22])$, indicating that CFT is superior to the other treatments. No notable change was found in the statistical significance of the outcomes except the $\mathrm{I}^{2}$ of $0 \%$.

\section{The CFT versus other treatments for disability/functional status for the long-term}

Regarding disability/functional status at the long-term period, data from the two studies $[19,21]$ were synthesised, and the forest plot is shown in Fig. 2e. The cumulated sample size of participants in the CFT and other treatments groups was 157 and 143, respectively. A statistically significant overall effect was detected $(P<0.0001, \mathrm{MD}[95 \% \mathrm{Cls}]=-0.84$ [-11.47--5.49]), indicating that the CFT is superior to other treatments in terms of disability/functional status at the long-term period. The $\mathrm{I}^{2}$ value was $0 \%$, indicating insignificant heterogeneity. The quality of the evidence using the GRADE approach was very low (Table 3 ).

\section{The CFT versus other treatments for FABQ score for the intermediate-term}

Regarding the fear of physical activity at the intermediate-term period, data from the two studies [19, 21] were synthesised, and the forest plot is shown in Fig. 2f. The cumulated sample size of participants in the CFT and other treatments groups was 157 and 143 , respectively. Statistically significant overall effect was detected $(P<0.0001, \mathrm{MD}[95 \% \mathrm{Cls}]=-3.01[-5.14--0.88])$, indicating that the CFT is superior to other treatments in terms of fear of physical activity at the intermediate-term period. The $\mathrm{I}^{2}$ value was $53 \%$, indicating moderate heterogeneity. The quality of the evidence using the GRADE approach was very low (Table 3).

\section{The CFT versus other treatments for fear of physical activity for the long-term}

Regarding fear of physical activity at the long-term period, data from the two studies $[19,21]$ were synthesised, and the forest plot is shown in Fig. $2 \mathrm{~g}$. The cumulated sample size of participants in the CFT and other treatments groups was 157 and 143, respectively. Statistically significant overall effect was detected $(P=0.02, \mathrm{MD}[95 \% \mathrm{Cls}]=-3.56[-6.43--0.68])$, indicating that the CFT is superior to other treatments in terms of fear of physical activity at the longterm period. The $\mathrm{I}^{2}$ value was $75 \%$, indicating substantial heterogeneity. The quality of the evidence using the GRADE approach was very low (Table 3 ). 
Table 3

A summary of the quality of the evidence using the GRADE approach

Quality assessment

No of Risk of bias

studies
Imprecision
Summary of findings

Inconsistency

\section{No of} participants
Pooled

standardised

mean

difference

$(95 \%$

confidence

intervals)

Pain for intermediate term

Serious risk of bias,
indicating
downgraded on level
due to there was
more than $25 \%$ of
participants from
studies.

studies.
Very serious

imprecision due to very

limited sample sizes

(fewer than 400

participants), and no

significant difference

rate down two levels

Significant$$
\text { (n) }
$$

\begin{tabular}{|c|c|c|}
\hline Very Serious & Not serious & Undetected \\
\hline $\begin{array}{l}\text { Downgraded } \\
\text { two levels due } \\
\text { to } I^{2}>75 \% \text {, } \\
\text { rate down two } \\
\text { levels }\end{array}$ & $\begin{array}{l}\text { Indirectness, } \\
\text { do not } \\
\text { downgrade }\end{array}$ & \\
\hline
\end{tabular}

$-0.69$

$(-1.57$ to

VERY

LOW
Quality of evidence

Pain for long term

Serious risk of bias,
indicating
downgraded on level
due to there was
more than $25 \%$ of
participants from
studies.

Very serious
imprecision due to very
limited sample sizes
(fewer than 400
participants), and no
significant difference
rate down two levels
Significant

Serious

Downgraded one level due to $\mathrm{l}^{2}>50 \%$, rate down one level

Not serious
Indirectness,
do not
downgrade

Undetected 300

$-0.45$

$(-0.94$ to $\oplus \bullet \bullet \bullet$

VERY

LOW

Disability/functional status for intermediate term$$
3
$$

Serious risk of bias,
indicating
downgraded on level
due to there was
more than $25 \%$ of
participants from
studies.

Serious
imprecision due to very
limited sample sizes
(fewer than 400
participants), rate down
one level

Very Serious

Serious

Undetected 333

$-0.78$

Downgraded Downgraded

two levels due one level

$(-1.47$ to

to $I^{2}>75 \%, \quad$ due to

$\begin{array}{ll}\text { rate down two } & \text { different } \\ \text { levels } & \text { sample }\end{array}$

$\oplus \mathrm{OO}$

Significant

Disability/functional status for long term

Serious risk of bias,
indicating
downgraded on level
due to there was
more than $25 \%$ of
participants from
studies.

Serious
imprecision due to very
limited sample sizes
(fewer than 400
participants), rate down
one level

Serious

Not serious

Undetected 300

$-0.67$

Downgraded one level due

to $\mathrm{I}^{2}>50 \%$,

Indirectness,

do not

$(-1.07$ to

downgrade

$-0.27)$

VERY

rate down one

level

Significant

Fear of physical activity for intermediate term

Serious risk of bias,
indicating
downgraded on level
due to there was
more than $25 \%$ of
participants from
studies.

Serious
imprecision due to very
limited sample sizes
(fewer than 400
participants), rate down
one level

Serious

Downgraded one level due to $\mathrm{I}^{2}>50 \%$, rate down one level

Significant

Fear of physical activity for long term

\begin{tabular}{|c|c|c|c|c|c|c|c|c|}
\hline \multirow[t]{2}{*}{2} & $\begin{array}{l}\text { Serious risk of bias, } \\
\text { indicating } \\
\text { downgraded on level } \\
\text { due to there was } \\
\text { more than } 25 \% \text { of } \\
\text { participants from } \\
\text { studies. }\end{array}$ & $\begin{array}{l}\text { Serious } \\
\text { imprecision due to very } \\
\text { limited sample sizes } \\
\text { (fewer than } 400 \\
\text { participants), rate down } \\
\text { one level }\end{array}$ & $\begin{array}{l}\text { Very Serious } \\
\text { Downgraded } \\
\text { two levels due } \\
\text { to } 1^{2}>75 \% \text {, } \\
\text { rate down two } \\
\text { levels }\end{array}$ & $\begin{array}{l}\text { Not serious } \\
\text { Indirectness, } \\
\text { do not } \\
\text { downgrade }\end{array}$ & Undetected & 300 & $\begin{array}{l}-0.60 \\
(-1.18 \text { to } \\
-0.01)\end{array}$ & $\begin{array}{l}\text { } О \\
\text { VERY } \\
\text { LOW }\end{array}$ \\
\hline & & Significant & & & & & & \\
\hline
\end{tabular}


To our knowledge, this is the first systematic review with the meta-analysis of RCTs examining the effect of the CFT in comparison to other treatments. A statistically significant benefit was detected in pain intensity for the long-term period, the disability/functional status and FABQ scores at the intermediate and long-term periods, but not in pain intensity for the intermediate-term period. It was also found that the quality of evidence in each meta-analysis was very low for all outcomes.

A statistically significant benefit was observed in the CFT in comparison to other treatments in the disability/functional status, but not in the pain intensity for the intermediate-term period. In addition, there was a statistically significant difference in pain intensity for the long-term period, but the effect was small. This finding may reflect the CFT characteristic, which aims to promote behavioural change and patient's self-management through a multifaceted approach, not to improve pain intensity [7]. Further, a caution may be required when the difference in the disability/functional status is interpreted from a clinical perspective. A statistically significant difference was found, but discussions may occur considering the clinically important difference. Intra-group improvements of $12 \%$ [21] and $14 \%$ [19] on the ODI have been reported in RCTs. Although there is no universally established clinically important difference for the ODI and the RMDQ scores, Copay et al. [24] suggested the use of the minimum clinically important difference (MCID) of $14.9 \%$ for group comparison in the ODI, and 5 points were suggested by studies for the RMDQ [25-27]. The MCID validation is best used for cohort studies and may be too stringent to be applied to RCTs; however, when the threshold of $14.9 \%$ for ODI and 5 for RMDQ were used for conservative interpretations of the results, the statistically significant differences detected by the CFT compared to other treatments in disability/functional status at each follow-up point would be negligible. Therefore, it may be prudent to interpret that the effect of the CFT in pain and disability/functional status is limited for now.

A statistically significant benefit was observed in the CFT compared to other treatments in the FABQ score. Although there is no universally established MCID for the FABQ, Monticone et al. [28] reported the MCID of 4 and George et al. [29] reported 13. When these thresholds are taken into consideration, the detected statistically significant differences of the FABQ by the CFT in comparison to other treatments may not be clinically important. Further studies using a measure for fear of movement with higher responsiveness may be required in the future.

In this study, GRADE was very low in outcomes of pain intensity, as well as the other outcomes including disability/functional staus and fear of phycial activity were very low. The main reason for downgrading is the impression regarding the smaller sample size which is less than 400 . Another reason was the risk of bias and inconsistency for downgrading. Furthermore, publication bias has not been assessed. The Cochrane Collaboration recommends ten or more studies to formally assess for publication bias [15]. Therefore, further RCTs are required to increase the overall evidence level of findings of the CFT effectiveness. Although the GRADE is improved with additional RCTs, there would be a barrier to strongly recommend the CFT in a clinical practice guideline, which is associated with equality for patients and feasibility in wide clinical practice. All three RCTs included in this study were undertaken by the same research group. This is because the CFT requires a certain level of knowledge and skills of the practitioner, and acquiring adequate skill to perform the CFT is not straightforward [30]. The magnitude of recommendation in a clinical practice guideline is reduced when equality for patients and feasibility are challenging [31]. Therefore, for strong recommendation of the CFT in clinical practice guidelines, a system to guarantee the skill level of the CFT must be established in the future.

\section{Limitations}

This study had two limitations. The first and greatest is the lack of identical treatments in the comparison group. A meta-analysis is necessary in this situation to gain specific understanding of CFT's effectiveness with a certain intervention. Second limitation was the search strategy. Only published RCTs were included in this study. Therefore, it is possible that there are reports that were not found. However, a manual search was performed as much as possible. A cross-referencing was also done, so the conclusions are not going to change significantly.

\section{Strength and suggestions}

Strengths of this systematic review include that this is the first summarize CFT's effectiveness. We found that all studies were reported only by the same study group and that no RCTs existed that compared CFT with CBT. Future RCTs are necessary to enhance the generalizability of the findings. Further, one merit of CFT versus CBT is the inclusion of biomedical approach by physical therapists to satisfy comprehensibility of the BPS components; therefore, future RCTs comparing CFT with CBT are required. Furthermore, in this review, only the fear of physical activity was synthesized as a psychological factor. In BPS, psychosocial factors other than fear of physical activity are included, such as pain, catastrophic thinking, self-efficacy, medical costs, sick leave duration, and presenteeism. Future RCTs with a variety of psychosocial factors are required to fully understand CFT's characteristics.

\section{Conclusion}

We have very little confidence that CFT is more effective than other interventions for reducing disability in the short-term, intermediate and long-term follow-up. The true is likely to be substantially different from the estimate of effect. CFT's effectiveness must be re-evaluated in the future in larger RCTs with low risk of bias and in comparisons with identical interventions.

\section{Abbreviations}

CFT: cognitive functional therapy, CNSLBP: Chronic nonspecific low back pain, BPS: The Bio-Psych-Social, CBT: Cognitive-behavioral therapy, LBP: Low back pain, RCTs: randomized controlled trials, GRADE: the Grading of Recommendations Assessment, Development and Evaluation, NRS: Numerical Rating Scale, ODI: Oswestry Disability Index, FABQ: Fear-Avoidance Beliefs Questionnaire, MDCS: Multidimensional Classification System, ROM: Range of Motion, RDQ: Roland-Morris Disability Questionnaire, HSCL-25: Hopkins Symptoms Checklist, PSQ: Patient Satisfaction Questionnaire, OMPQ: Orebro Musculoskeletal Pain Questionnaire, CNSLBP: chronic non-specific low back pain, BBQ: Back Beliefs Questionnaire, PSEQ: Pain Self-Efficacy Questionnaire, CSQ: Coping Strategies

Loading [MathJax]/jax/output/CommonHTML/jax.js 
Questionnaire, SHC: Subjective Health Complaints Inventory, DASS: Depression, Anxiety and Stress Scale, MCID: Minimum clinically important difference, MD: The mean difference, SMD: the standardised mean difference

\section{Declarations}

\section{Ethics approval and consent to participate}

Not applicable.

\section{Patient consent for publication}

Not required.

\section{Availability of data and materials}

Not applicable.

\section{Competing interests}

None declared (All authors).

\section{Funding}

No funding source was provided for this study.

\section{Author's contributions}

Conceptualization: Takahiro Miki, Yu Kondo, Hiroshi Kurakata.

Data curation: Takahiro Miki, Yu Kondo, Hiroshi Kurakata, Eva Buzasi

Formal analysis: Takahiro Miki, Hiroshi Kurakata

Investigation: Takahiro Miki, Yu Kondo, Hiroshi Kurakata, Eva Buzasi

Methodology: Takahiro Miki, Hiroshi Kurakata

Project administration: Hiroshi Kurakata, Tsuneo Takebayashi, Hiroshi Takasaki.

Supervision: Hiroshi Takasaki, Tsuneo Takebayashi.

Visualization: Tsuneo Takebayashi.

Writing - original draft: Takahiro Miki, Yu Kondo, Hiroshi Takasaki.

\section{Acknowledgements}

The authors would like to thank Enago (www.enago.jp) for the English language review.

\section{References}

1. Oliveira CB, Maher CG, Pinto RZ, Traeger AC, Lin CC, Chenot JF, et al. Clinical practice guidelines for the management of non-specific low back pain in primary care: an updated overview. Eur Spine J. 2018;27(11):2791-803.

2. Foster NE, Anema JR, Cherkin D, Chou R, Cohen SP, Gross DP, et al. Prevention and treatment of low back pain: evidence, challenges, and promising directions. Lancet. 2018;391(10137):2368-83.

3. Beissner K, Henderson CR, Jr., Papaleontiou M, Olkhovskaya Y, Wigglesworth J, Reid MC. Physical therapists' use of cognitive-behavioral therapy for older adults with chronic pain: a nationwide survey. Phys Ther. 2009;89(5):456-69.

4. Jull G. Biopsychosocial model of disease: 40 years on. Which way is the pendulum swinging? Br J Sports Med. 2017;51(16):1187-8.

5. Hall A, Richmond H, Copsey B, Hansen Z, Williamson E, Jones G, et al. Physiotherapist-delivered cognitive-behavioural interventions are effective for low back pain, but can they be replicated in clinical practice? A systematic review. Disabil Rehabil. 2018;40(1):1-9.

6. Urits I, Hubble A, Peterson E, Orhurhu V, Ernst CA, Kaye AD, et al. An Update on Cognitive Therapy for the Management of Chronic Pain: a Comprehensive Review. Curr Pain Headache Rep. 2019;23(8):57.

7. O'Sullivan PB, Caneiro JP, O'Keeffe M, Smith A, Dankaerts W, Fersum K, et al. Cognitive Functional Therapy: An Integrated Behavioral Approach for the Targeted Management of Disabling Low Back Pain. Phys Ther. 2018;98(5):408-23.

8. Mitchell T, Beales D, Slater H, O'Sullivan P. Musculoskeletal Clinical Translation Framework: From Knowing to Doing. School of Physiotherapy and Exercise Science; 2017.

Loading [MathJax]/jax/output/CommonHTML/jax.js 
9. Wertli MM, Rasmussen-Barr E, Held U, Weiser S, Bachmann LM, Brunner F. Fear-avoidance beliefs-a moderator of treatment efficacy in patients with low back pain: a systematic review. Spine J. 2014;14(11):2658-78.

10. Ghogomu EA, Maxwell LJ, Buchbinder R, Rader T, Pardo Pardo J, Johnston RV, et al. Updated method guidelines for cochrane musculoskeletal group systematic reviews and metaanalyses. J Rheumatol. 2014;41(2):194-205.

11. Maher CG, Sherrington C, Herbert RD, Moseley AM, Elkins M. Reliability of the PEDro scale for rating quality of randomized controlled trials. Phys Ther. 2003;83(8):713-21.

12. Olivo SA, Macedo LG, Gadotti IC, Fuentes J, Stanton T, Magee DJ. Scales to assess the quality of randomized controlled trials: a systematic review. Phys Ther. 2008;88(2):156-75.

13. Boyles R, Toy P, Mellon J, Jr., Hayes M, Hammer B. Effectiveness of manual physical therapy in the treatment of cervical radiculopathy: a systematic review. J Man Manip Ther. 2011;19(3):135-42.

14. Coppola SM, Collins SM. Is physical therapy more beneficial than unsupervised home exercise in treatment of post surgical knee disorders? A systematic review. Knee. 2009;16(3):171-5.

15. Atkins D, Eccles M, Flottorp S, Guyatt GH, Henry D, Hill S, et al. Systems for grading the quality of evidence and the strength of recommendations I: critical appraisal of existing approaches The GRADE Working Group. BMC Health Serv Res. 2004;4(1):38.

16. Furlan AD, Malmivaara A, Chou R, Maher CG, Deyo RA, Schoene M, et al. 2015 Updated Method Guideline for Systematic Reviews in the Cochrane Back and Neck Group. Spine. 2015;40(21):1660-73.

17. Takasaki H, May S. Mechanical diagnosis and therapy has similar effects on pain and disability as 'wait and see' and other approaches in people with neck pain: a systematic review. J Physiother. 2014;60(2):78-84.

18. Deeks JJ HJ, Altman DG. Chapter 10: Analysing data and undertaking meta-analyses. Cochrane. 2019. http://www.training.cochrane.org/handbook. Accessed 26 Feb 2021.

19. Vibe Fersum K, O'Sullivan P, Skouen JS, Smith A, Kvale A. Efficacy of classification-based cognitive functional therapy in patients with non-specific chronic low back pain: a randomized controlled trial. Eur J Pain. 2013;17(6):916-28.

20. Ng L, Caneiro JP, Campbell A, Smith A, Burnett A, O'Sullivan P. Cognitive functional approach to manage low back pain in male adolescent rowers: a randomised controlled trial. Br J Sports Med. 2015;49(17):1125-31.

21. O'Keeffe M, O'Sullivan P, Purtill H, Bargary N, O'Sullivan K. Cognitive functional therapy compared with a group-based exercise and education intervention for chronic low back pain: a multicentre randomised controlled trial (RCT). Br J Sports Med. 2020;54(13):782-89.

22. Vibe Fersum K, Smith A, Kvale A, Skouen JS, O'Sullivan P. Cognitive functional therapy in patients with non-specific chronic low back pain-a randomized controlled trial 3-year follow-up. Eur J Pain. 2019;23(8):1416-24.

23. Fernandez J, Ferreira AS, Castro J, Correia LCL, Meziat-Filho N. Comment on the paper "Cognitive functional therapy in patients with non specific chronic low back pain", by Vibe Fersum et al. Eur J Pain. 2019;23(8):1574-5.

24. Copay AG, Glassman SD, Subach BR, Berven S, Schuler TC, Carreon LY. Minimum clinically important difference in lumbar spine surgery patients: a choice of methods using the Oswestry Disability Index, Medical Outcomes Study questionnaire Short Form 36, and Pain Scales. The Spine Journal.

2008;8(6):968-74.

25. Ostelo RW, Deyo RA, Stratford P, Waddell G, Croft P, Von Korff M, et al. Interpreting change scores for pain and functional status in low back pain: towards international consensus regarding minimal important change. Spine (Phila Pa 1976). 2008;33(1):90-4.

26. Stratford PW, Binkley JM. Measurement properties of the RM-18. A modified version of the Roland-Morris Disability Scale. Spine (Phila Pa 1976). 1997;22(20):2416-21.

27. Lee MK, Yost KJ, McDonald JS, Dougherty RW, Vine RL, Kallmes DF. Item response theory analysis to evaluate reliability and minimal clinically important change of the Roland-Morris Disability Questionnaire in patients with severe disability due to back pain from vertebral compression fractures. The Spine Journal. 2017;17(6):821-9.

28. Monticone M, Frigau L, Vernon H, Rocca B, Giordano A, Vullo SS, et al. Reliability, responsiveness and minimal clinically important difference of the two Fear Avoidance and Beliefs Questionnaire scales in Italian subjects with chronic low back pain undergoing multidisciplinary rehabilitation. Eur $\mathrm{J}$ Phys Rehabil Med. 2020;56(5):600-6.

29. George SZ, Fritz JM, McNeil DW. Fear-avoidance beliefs as measured by the fear-avoidance beliefs questionnaire: change in fear-avoidance beliefs questionnaire is predictive of change in self-report of disability and pain intensity for patients with acute low back pain. Clin J Pain. 2006;22(2):197-203.

30. Holopainen R, Piirainen A, Karppinen J, Linton SJ, O'Sullivan P. An adventurous learning journey. Physiotherapists' conceptions of learning and integrating cognitive functional therapy into clinical practice. Physiotherapy Theory and Practice. 2020:1-18.

31. Kojimahara N, Nakayama T, Morizane T, Yamaguchi N, Yoshida M. Minds Manual for Guideline Development 2017. Tokyo: Japan Council for Quality Health Care. 2017.

\section{Figures}



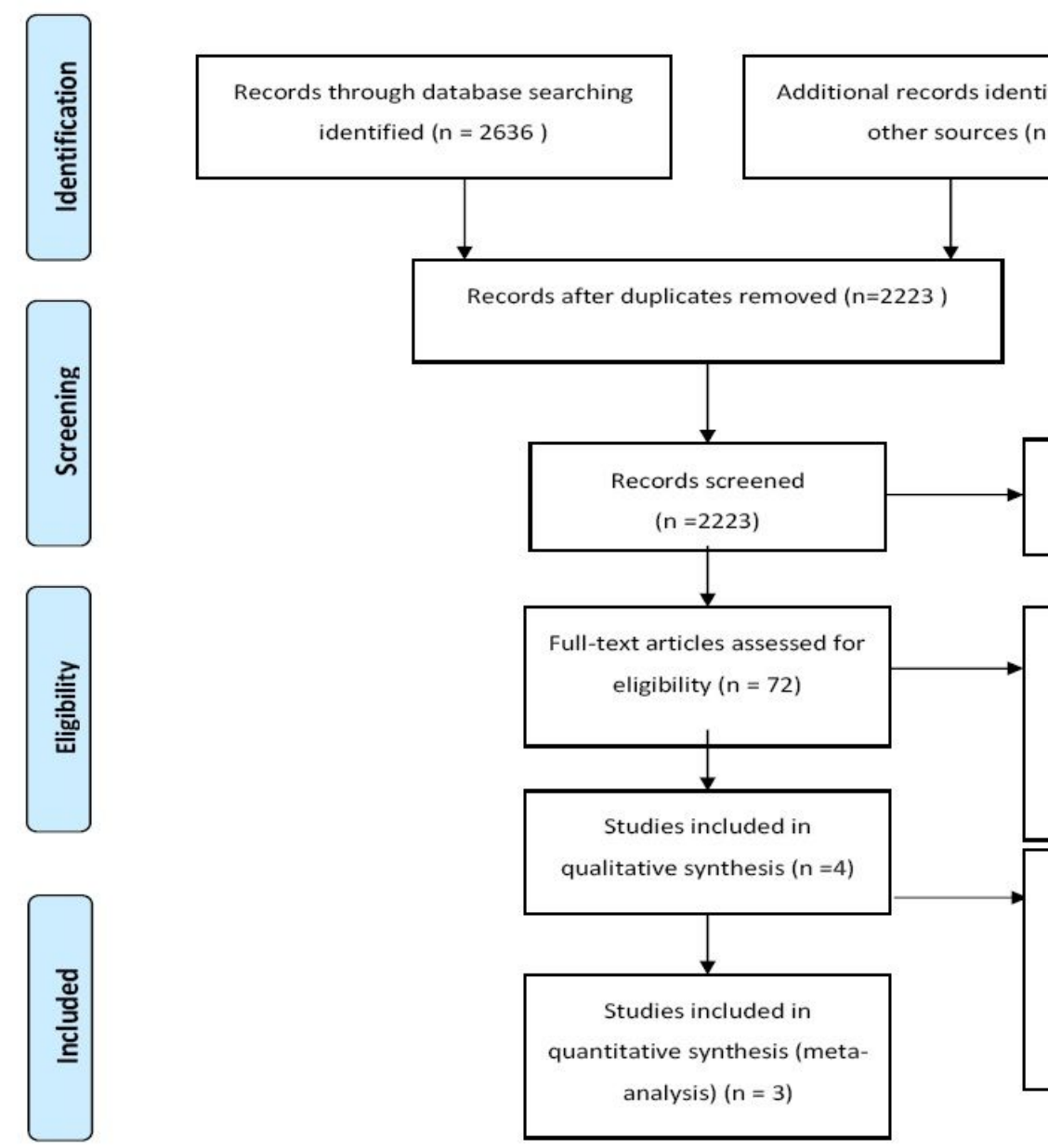

Records excluded

( $n=2151$ )

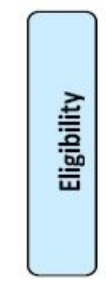

Full-text articles excluded

with reasons $(n=68)$

Not RCT $(n=8)$

Not LBP $(n=3)$

Not CFT $(m=57)$

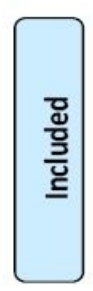

Full-text articles excluded, with reasons

$$
(\mathrm{n}=1)
$$

Follow up study of the

identical sample

\section{Figure 1}

Flow diagram of search strategy. 


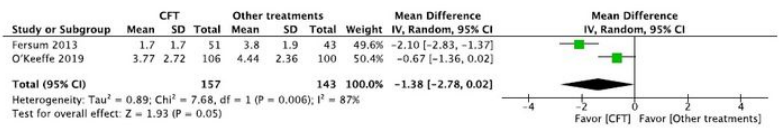

Figure 2a.

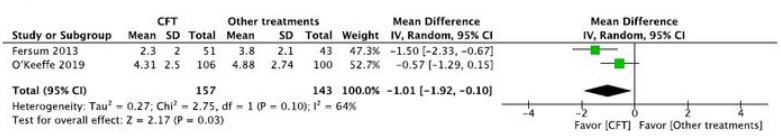

Figure $2 b$.

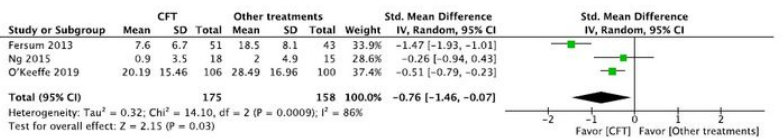

Figure 2c

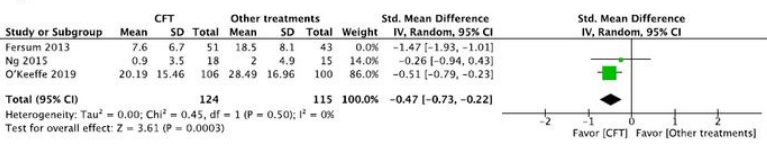

Figure 2d.

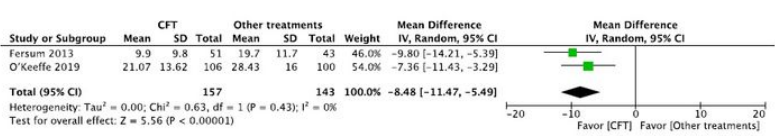

Figure 2e.

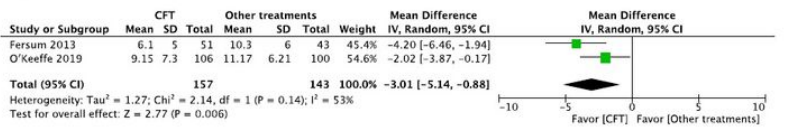

Figure $2 f$.

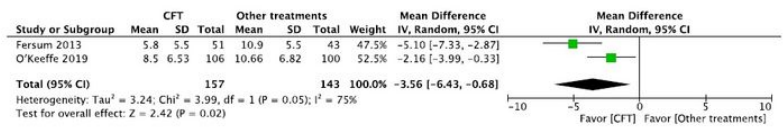

Figure 2g.

\section{Figure 2}

Meta-analysis. 2a. Pain for the intermediate-term period 2b. Pain for the long-term period 2c. Disability/functional status for the intermediate-term period 2d. Disability/functional status for the intermediate-term period (Sensitivity Analysis) 2e. Disability/functional status for the long-term period $2 f$. Fear of physical activity for the intermediate-term period $2 \mathrm{~g}$. Fear of physical activity for the long-term period Abbreviations: CFT; Cognitive Functional Therapy Positive Scores favor the CFT and negative scores favor other treatments. Intermediate term: $\geq 3$ months and $<12$ months; Long term: $\geq 12$ months

\section{Supplementary Files}

This is a list of supplementary files associated with this preprint. Click to download.

- Apx2searchstragery.docx

- PRISMA2009checklist.doc

- renamedc345c.docx 